\title{
Ocorrência de Cuiaraneiras em Salinópolis, no Pará, Brasil
}

\author{
Occurrence of Buchenavia in the municipality of Salinópolis, state \\ of Pará, Brazil
}

Gutemberg Armando Diniz Guerra - Doutorado em Socio Economie Du Developpement, Ecole des Hautes Études en Sciences Sociales, EHESS, França. Mestrado em Desenvolvimento Sustentável do Trópico Úmido. Universidade Federal do Pará, UFPA, Brasil. Especialização em Recherches Comparatives Sur Le Developpement, Ecole des Hautes Études en Sciences Sociales, EHESS, França. Especialização em Métodos de Planejamento Urbano e Regional, Secretaria de Planejamento Ciência e Tecnologia do Estado da Bahia. Graduação em Engenharia Agronômica. Universidade Federl da Bahia, UFBA, Brasil. E-mail: gguerra@ufpa.br

Rosildo Santos Paiva - Doutorado em Oceanografia (Oceanografia Biológica), Universidade de São Paulo, USP, Brasil. Mestrado em Biologia Vegetal, Universidade Federal de Pernambuco, UFPE, Brasil. Graduação em Licenciatura Plena em Ciências Biológicas, UFPA. Graduação em Licenciatura Curta em Ciências, UFPA. E-mail: rpaiva@ufpa.br

\section{Resumo}

Este ensaio trata de cuiaraneiras (Buchenavia grandis, Ducke), espécie à qual se atribui ter servido para dar nome ao distrito de Cuiarana, em Salinópolis, no Pará. O significado da palavra cuiarana se reporta à semelhança com a planta da cuia ou cuieira (Crescentia cujete L). No caso específico do registro da ocorrência desta espécie em Salinópolis, um indivíduo se torna histórico com um significado simbólico efetivo para os moradores do lugar, habitado originalmente por pescadores e com uma crescente população de veranistas. Partindo dessa motivação, buscou-se identificar a ocorrência dessa espécie no município de Salinópolis, em particular na sede municipal e no distrito de Cuiarana. Para isso foram feitas incursões na área municipal e entrevistas com moradores do local entre os meses de dezembro de 2013 a agosto de 2014, em particular em lugares onde havia espécimes reconhecidos pelo porte exuberante e serviço ambiental que tem prestado. O que se verifica é que a espécie é utilizada como ornamental e para sombrear áreas de entretenimento em logradouros públicos e privados como ruas, praças, residências e hotéis.

\section{Palavras-chave}

Toponímia. Plantas Ilustres. Natureza. Cultura. Serviço Ambiental.

\begin{abstract}
This essay studies the Buchenavia [Cuiaraneira Trees - Buchenavia grandis, Ducke], species of which the district of Cuiarana - in the municipality of Salinópolis, State of Pará - was named after. The meaning of the word cuiarana leads us to the term 'bowl' or still the Calabash tree [Crescentia cujete L]. Specifically about this study, a person becomes notable with a symbolic importance to the local residents, originally inhabited by fishermen with an increasing number of vacationers. From this observation, it was pursued to identify the occurrence of such species in the municipality of Salinópolis, particularly in the urban area and in the district of Cuiarana. For that, trips to the municipality and interviews with local residents between the months of December 2013 and March 2014 were made, particularly in places where the species was identified by its exuberant set and the environment service that has provided. It has been observed that the species is used as decoration and for shading at entertainment areas both in public and private places such as streets, squares, houses and hotels.
\end{abstract}

\section{Keywords}

Toponymy. Notable Plants. Nature. Culture. Environmental Service. 


\section{1 ÁRVORES QUE NOMINAM LUGARES NO PARÁ}

Algumas árvores tornam-se patrimônio público pelo significado dos seus papéis na denominação de lugares. Às vezes, elas permanecem como endêmicas, frequentemente escasseiam e desaparecem, outras vezes são plantadas, restauradas ou replantadas para representar e ilustrar toponímias (nomes de lugares) ou refazer paisagens. O nome do Brasil tem como referência uma espécie arbórea (Caesalpina echinata, Lam) muito explorada desde o primeiro contato dos europeus para a utilização de corantes nela existentes para a tinturaria. Fugindo a nomes que foram dados a cidades em outros estados da federação brasileira e no mundo, no Estado do Pará pode-se contar com os nomes de municípios e localidades listados a seguir, todos fazendo referência a gêneros e espécies comuns à região, ou ainda nomes genéricos lembrando a paisagem ou reportando-se a acidentes geográficos e naturais associados à vegetação: Castanhal e Castanheira (Bertholethia excelsa H. B. K.), Amoreiras (Morus sp), Laranjeiras (Citrus spp), Ananindeua (Symphonia globulifera L.f.), Anajás (Attalea sp), Breu Branco (Protium heptaphyllum (Aubl.) March), Cumaru do Norte (Dipteryx odorata (Aubl.) Wild.), Curuá ( Orbignya spp), Floresta do Araguaia (nome genérico reportando-se à vegetação originária do município), Limoeiro do Ajuru (Chrysobalanus icaco L), Marituba (Geoffroea sp), Timboteua (Paullinia spp), Pau d'Arco (Tabebuia serratifolia (Vahl) Nich), Primavera (referência a estação das flores), São Domingos do Capim, Sapucaia (Lecythis pisonis Camb.) e Tucumã (Astrocaryum vulgare Mart. ). A lista não é exaustiva e dá ideia da influência da vegetação na toponímia, como é o do caso que se explora neste ensaio.

Do ponto de vista da importância da manutenção de plantas nativas como forma de manter carbono na terra evitando sua emissão para a atmosfera, Nogueira et al. (2007) colocam a cuiaraneira na lista daquelas cuja densidade da madeira merece atenção. Quando se fala em serviço ambiental, tem sido recorrente no debate acadêmico, científico e político a tendência a estabelecer valores para os benefícios que a vegetação ou os ecossistemas oferecem, desde a garantia da biodiversidade, a purificação do ar e da água, a retenção de carbono, a estética e uma infinidade de possibilidades de usos da natureza que poderiam ser quantificados e monetarizados (CONSTANZA, D’ARGE, 1997; LIVING..., 2005).

Este artigo se propõe a descrever a ocorrência e os usos dessa planta nativa da Amazônia que vem sendo preservada por características que fogem ao padrão geral de enquadramento pelos que se apropriam de novas terras e impõem cultivos consagrados, eliminando os nativos e menos conhecidos pelos estrangeiros. O serviço ambiental que ela oferece é basicamente o do bem- 
estar provocado pela sombra refrescante em ambientes ensolarados do litoral amazônico paraense assim como o aspecto estético que apresenta, conformandose à poda e possibilitando um formato que lembra ao de uma sombrinha ou de um teto com aspecto diferenciado. Pode-se ressaltar também o fato de que possui resistência suficiente para suportar cadeiras de balanço, redes e equipamentos que permitem o repouso ou o assento em seus ramos e sob o seu abrigo.

A metodologia utilizada para essa pesquisa foi a de entrevistas com pessoas estratégicamente selecionadas por serem nativas e/ou habitarem no município de Salinópolis, terem conhecimento sobre as plantas dessa espécie com as quais tinham contato e de outros exemplares existentes nas proximidades ou circunscritas ao município estudado. Foram entrevistadas 13 pessoas com essas características, em incursões feitas durante os anos de 2013 e 2014.

\section{CUIARANA DOS PESCADORES, VERANISTAS E APOSENTADOS}

A $220 \mathrm{~km}$ de Belém, de acesso pela BR-316 e depois pela PA-124, rodovias pavimentadas que dão acesso ao município de Salinas, o vilarejo continua com os aspectos de colônia pesqueira, com porto e praias em que todos os dias homens e mulheres chegam com suas redes e samburás trazendo espécies marinhas como bijupirá (Rachycentron canadum), pescada amarela (Cynoscion acoupa), dourada (Brachyplathystoma flavicans), piraíba (Brachyplathystoma filamentosum), gó (Macrodon ancylodon), pratiqueira (Mugil curema), cioba (Lutjanus analis), serra (Pristis) e outras utilizadas como alimentares incorporadas às refeições das famílias ou vendidas aos atravessadores que levam o produto para os mercados ou frigoríficos da região. Existem os tempos de peixe, mariscos e camarões, obedecendo a uma sazonalidade na oferta, um critério que impõe aos pescadores um ritmo próprio em suas atividades.

A população do vilarejo atinge a cifra estimada de 250 famílias com 1400 pessoas, segundo um dos 4 agentes de saúde que atuam no distrito, ENDM. Pela contagem oficial, o município de Salinópolis conta com 37.421 habitantes (IBGE, 2010).

Pelo acesso facilitado, clima ventilado e caráter bucólico, o povoado tem sido buscado por veranistas de cidades próximas do Pará e por visitantes de outros estados. Conta com uma infraestrutura de hotéis e pousadas, sendo comum o aluguel de residências, quartos e quitinetes nos períodos de veraneio. É um porto onde os amantes da pesca artesanal têm feito parada tanto que os habitantes locais mantêm a tradição de uma regata de embarcações típicas da região. 
Para efeito desta pesquisa, utilizou-se da estratégia de entrevistas rápidas, com perguntas abertas aos moradores de Cuiarana e Salinópolis sobre o conhecimento da presença de cuiaraneiras no município, após o que se fez a checagem das informações fornecidas pelos entrevistados, verificando-se a existência das mesmas in loco. Concordando com Cervo e Bervian (1996, p. 136), a entrevista "é conversa orientada para um objetivo definido: recolher, através de interrogatório do informante, dados para a pesquisa". Nos locais de existência dos indivíduos vegetais pesquisados, fez-se a interrogação aos proprietários ou trabalhadores dos estabelecimentos sobre o conhecimento que tinham daqueles exemplares, ora confirmando-se ora negando-se a sua existência ou identificação. Procurou-se entrevistar principalmente pessoas que habitavam a localidade e demonstravam conhecimento sobre as espécies vegetais existentes na paisagem, interrogando-se basicamente sobre se sabiam onde existiriam espécimes da cuiaraneira. Nem sempre esta era a primeira pergunta, tentando-se manter o foco, sem ser demasiado indiscreto e intempestivo na abordagem.

Foram realizadas coleta e identificação do exemplar existente no porto de Cuiarana e confirmação da identificação dos outros exemplares por comparações com aquelas exsicatas feitas com material desta primeira. Os informantes privilegiados nessa pesquisa foram moradores de Cuiarana e de Salinópolis encontrados nos locais onde se encontravam os exemplares repertoriados, atingindo-se o número de 13 pessoas. As principais perguntas feitas procuravam qualificar o informante pela sua relação com a localidade e com a espécie estudada, assim como o conhecimento que detinham sobre as qualidades desta.

\section{OCORRÊNCIAS DE CUIARANEIRAS EM CUIARANA E NA PRAIA DO FAROL VELHO, SALINÓPOLIS, NO PARÁ, BRASIL}

Conversando com EBS, 43 anos, natural de Gama, DF, há 14 anos em Salinópolis e 2 em Cuiarana, funcionário do Restaurante Marujo's, ele disse, primeiramente $^{1}$ que as únicas cuiaraneiras que ele conhece no município são a que se encontra no porto de Cuiarana, bem na encosta onde está o seu local de trabalho, e outra que se situa na praia do Farol Velho, em Salinas, onde se localiza a matriz do restaurante do qual é empregado. Em uma segunda entrevista ${ }^{2}$, fez referência, com precisão, da existência de uma cuiaraneira na rua da Pousada

\footnotetext{
Informação verbal quando da coleta botânica em 9 de novembro de 2013, à sombra da cuiaraneira, em Cuiarana, Salinópolis, Pará.

2 Esta segunda entrevista ocorreu na manhã de 22 de março de 2014, em Cuiarana, junto à cuiaraneira, no restaurante onde trabalha, em Cuiarana.
} 
Farol Velho e duas outras que estariam em residências cujo acesso e visão destas poderia ser feito pela praia. Perguntado sobre a serventia desta árvore, EBS diz que ela apenas serve de sombra. Acrescenta que o nome cuiaraneira significa falsa cuieira, porque ela difere da original e que não dá o fruto conhecido por cuia, muito utilizado na região para a fabricação de utensílios domésticos.

$\mathrm{Na}$ condição em que se encontra o exemplar histórico que deu nome à localidade, sob impacto da ampliação do restaurante, é evidente a intenção de manter a cuiaraneira no local, aparentemente preservada de uma supressão imediata. Segundo EBS, o dono do restaurante, o sr. CP, é fervoroso defensor da árvore e quer vê-la preservada a qualquer custo.

Checando a informação fornecida por EBS, encontrou-se a cuiaraneira representada na Figura 1, em residência próxima à praia do Farol Velho. Nesta árvore constatou-se que o formato horizontalizado da copa permite a fixação de luminárias e equipamentos como redes de descanso e balanço, além de fornecer sombra para o estacionamento de veículos e uso pelos residentes como se fosse uma varanda.

Figura 1 - Cuiaraneira em forma de sombrinha na rua da Pousada do Farol Velho

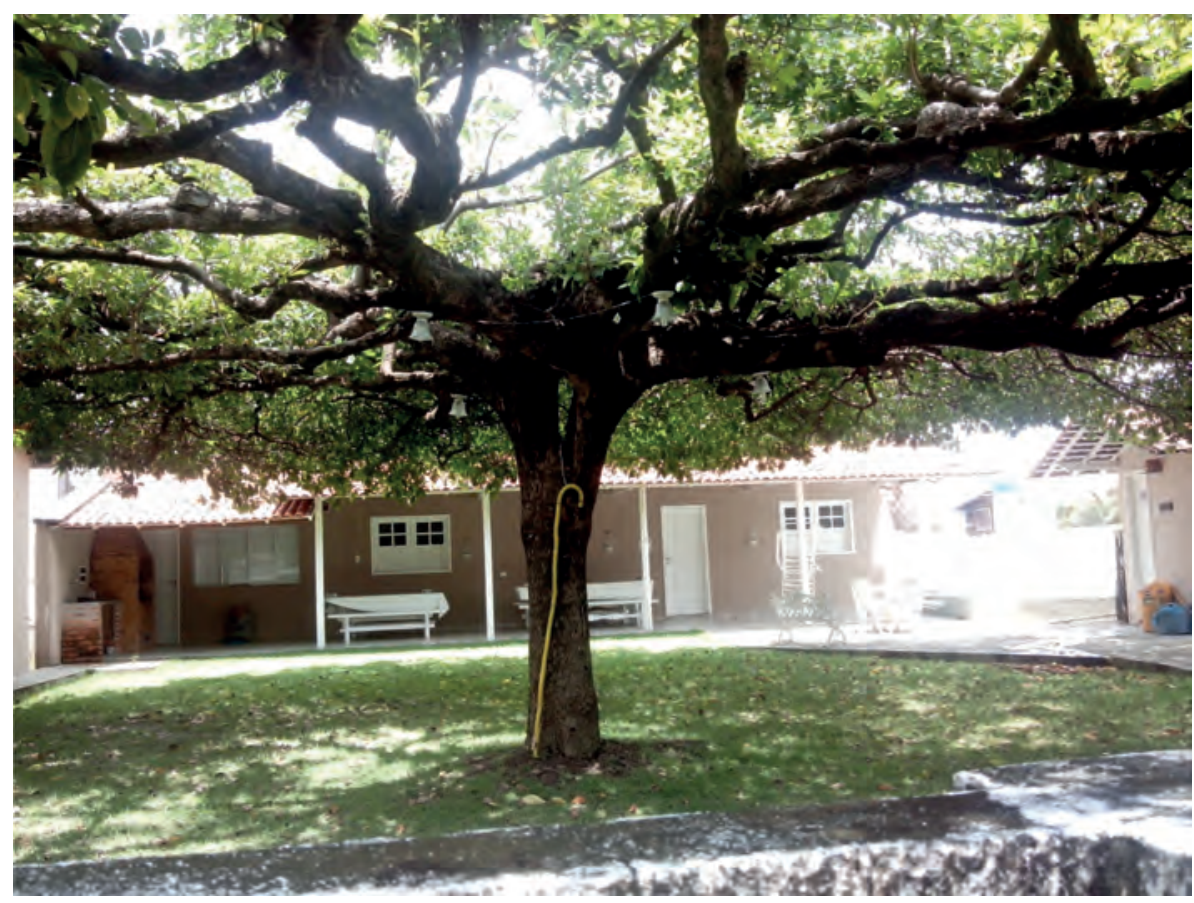

Fonte: Guerra (mar. 2014) 
VTC, natural de Cuiarana, 34 anos, filho de pais migrantes há mais de trinta anos para o lugar, garçom na matriz do restaurante Marujos, na praia do Farol Velho em Salinópolis, disse, no primeiro contato ${ }^{3}$, que havia muitas cuiaraneiras na localidade onde se situa aquela famosa, mas que apenas ela restou como representante daquela espécie. O fato é que ela se constitui em uma referência, seja pela representação que fazem dela mesma, seja pelo que de abrigo serve para seres mitológicos como a mucura branca e o camaleão dourado aos quais os moradores do povoado frequentemente fazem menção. Em um segundo contato $^{4}$ ele fez referência a uma árvore nova, da mesma espécie, no mesmo povoado de Cuiarana, além de indicar outro exemplar existente bem ao lado do seu local de trabalho (Figura 2), mostrar outro na estrada de acesso à praia do Farol Velho, e fazer menção a outros indivíduos, um que estaria no Hotel Atalaia Inn, e outro do qual já se tinha referência, perto da Pousada Farol Velho. Confirmou a informação sobre a existência de outros exemplares em residências na beira da praia. Nesse segundo contato verificou-se, portanto, um aumento do grau de informação que ele detinha quando entrevistado pela primeira vez. Em incursão para checagem destas informações, verificou-se que a indicação de indivíduos no Hotel Atalaia Inn não se confirmou, mas se identificou a presença de cinco exemplares na residência ao lado deste hotel, entre as quais se destacava uma das plantas com uma copa horizontalizada e onde se verificava a presença de equipamentos servindo de assento pendurados e redes de descanso, além de uma luminária indicando o uso noturno do ambiente propiciado pela copa daquela árvore.

Continuando a checagem das informações dadas por VTC, encontrou-se na rua Verde Mar, que dá acesso à praia do Farol Velho, um frondoso exemplar de cuiaraneira. Conversando com JS, 22 anos, nascido em Salinópolis, trabalhando na casa em cujo terreno se encontra o exemplar, ele disse ter sido interpelado por um senhor que se disse dono do terreno, em data que não soube precisar, mas que teria sido há uns três anos passados da data desta entrevista (22 de março de 2014). Este senhor teria informado que ele mesmo teria plantado a cuiaraneira e que isto teria sido há uns trinta anos. JS dá crédito a esta informação acrescentando que outros caseiros mais antigos do que ele teriam confirmado este dado sobre a avançada idade da planta.

Informação verbal de 8 de novembro de 2013, no restaurante Marujo, na praia do Farol Velho, em Salinópolis, Pará

4 No dia 22 de março de 2014, no Restaurante Marujo’s, na praia do Farol Velho. 
Figura 2 - Cuiaraneira em residência junto ao Restaurante Marujo's, na praia do Farol Velho

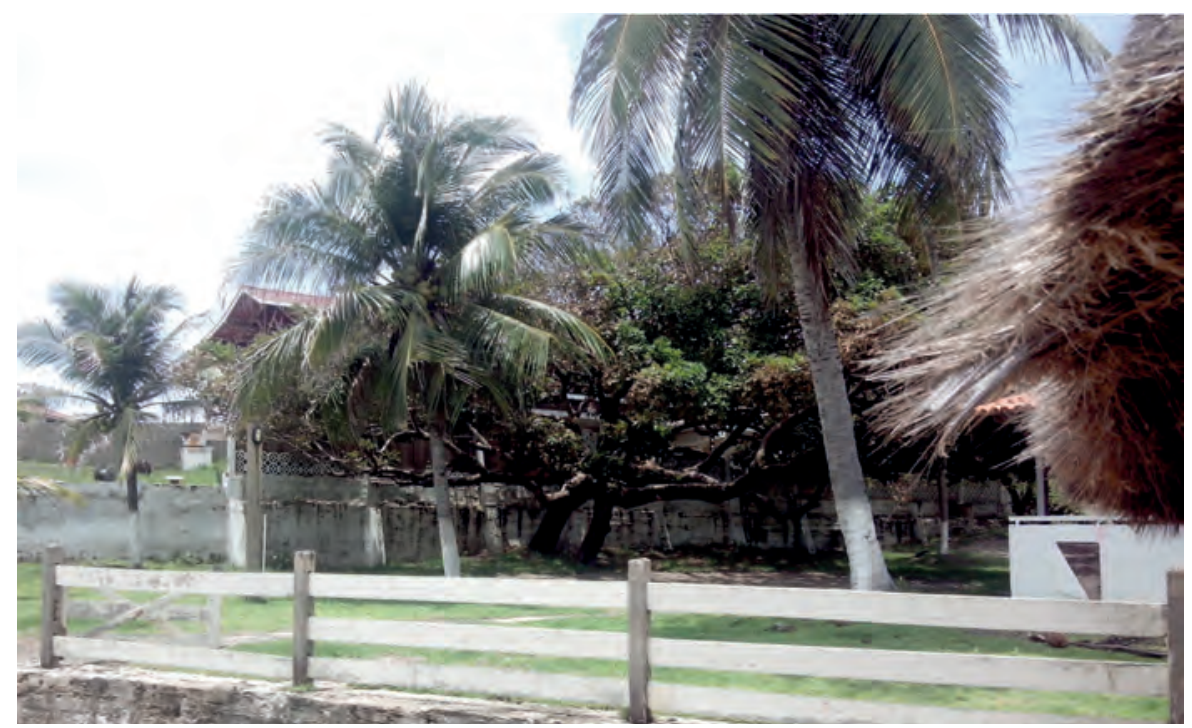

Fonte: Guerra (mar. 2014)

Em Cuiarana, ainda seguindo as informações de VTC, encontrou-se a cuiaraneira por ele referida, na casa do senhor RSL, 37 anos, pintor, nascido em Belém e morador de Cuiarana há mais de 20 anos. Segundo ele, a árvore foi plantada por ele, em homenagem ao lugar onde morava, e ofereceu duas mudas da planta e uma semente. Disse ter trabalhado durante 6 anos no Amazônia Atlântico Hotel Resort, localizado em Cuiarana, onde existiria uma cuiaraneira nas proximidades da piscina. Foi de lá que ele trouxera a semente que originou a que possui plantada no terreno de sua casa ${ }^{5}$.

Verificando a informação do sr. RSL sobre a cuiaraneira existente no Amazônia Atlântico Hotel Resort, encontraram-se três exemplares. Dois nas imediações da piscina (Figura 3) e um atrás do restaurante (Figura 4).

RSC, 35 anos, natural de Cuiarana, trabalhando no resort há 11 anos como zelador, atribui à planta o papel de sombrear a área próxima ao equipamento. Perguntado $^{6}$ sobre a emissão de sementes e folhas que poderiam prejudicar a limpeza da piscina, ele disse que apenas no verão há uma maior produção e queda de folhas e sementes, mas que não chega a ser um problema para ele que é responsável pelo serviço de limpeza. Este comportamento do vegetal pode ser um determinante de sua escolha como árvore de sombreamento nas áreas referidas.

\footnotetext{
Informação confirmada em 23 de março de 2014.

6 Entrevista feita em 23 de março de 2014.
} 
Figura 3 - Cuiaraneira no Amazônia Atlântico Hotel Resort, em Cuiarana

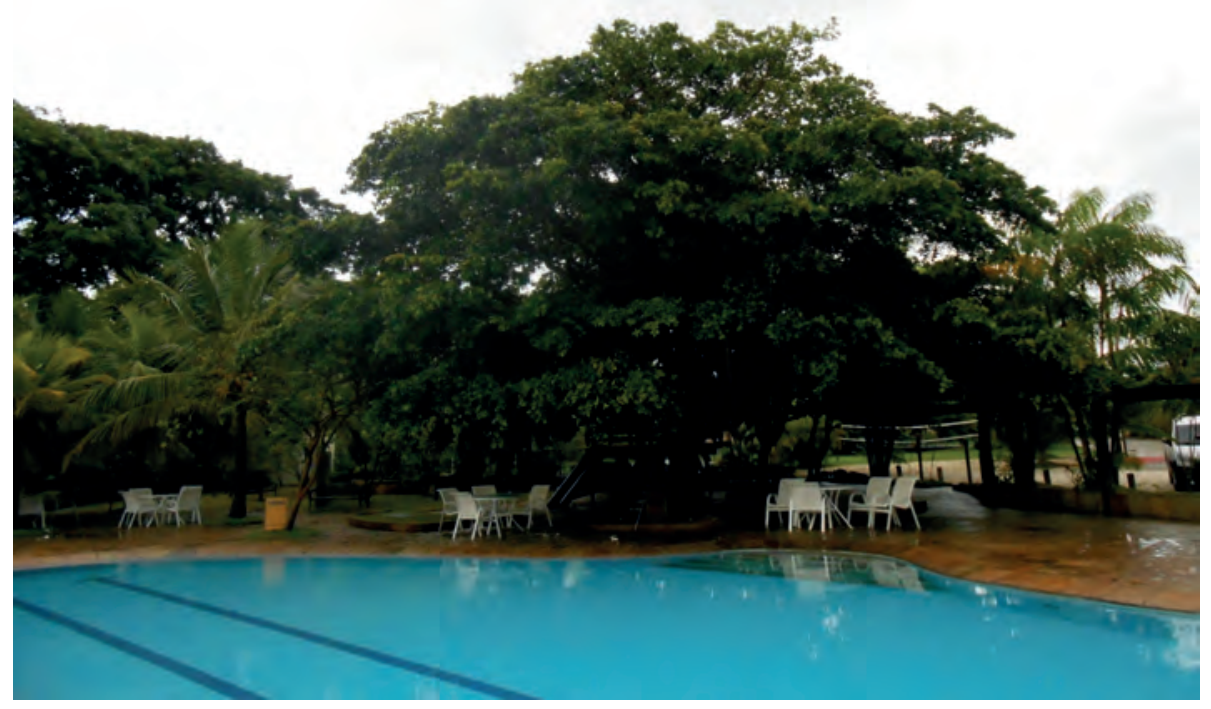

Fonte: Guerra (mar. 2014)

Figura 4 - Cuiaraneiras próximas ao restaurante do Amazônia Atlântico Hotel Resort

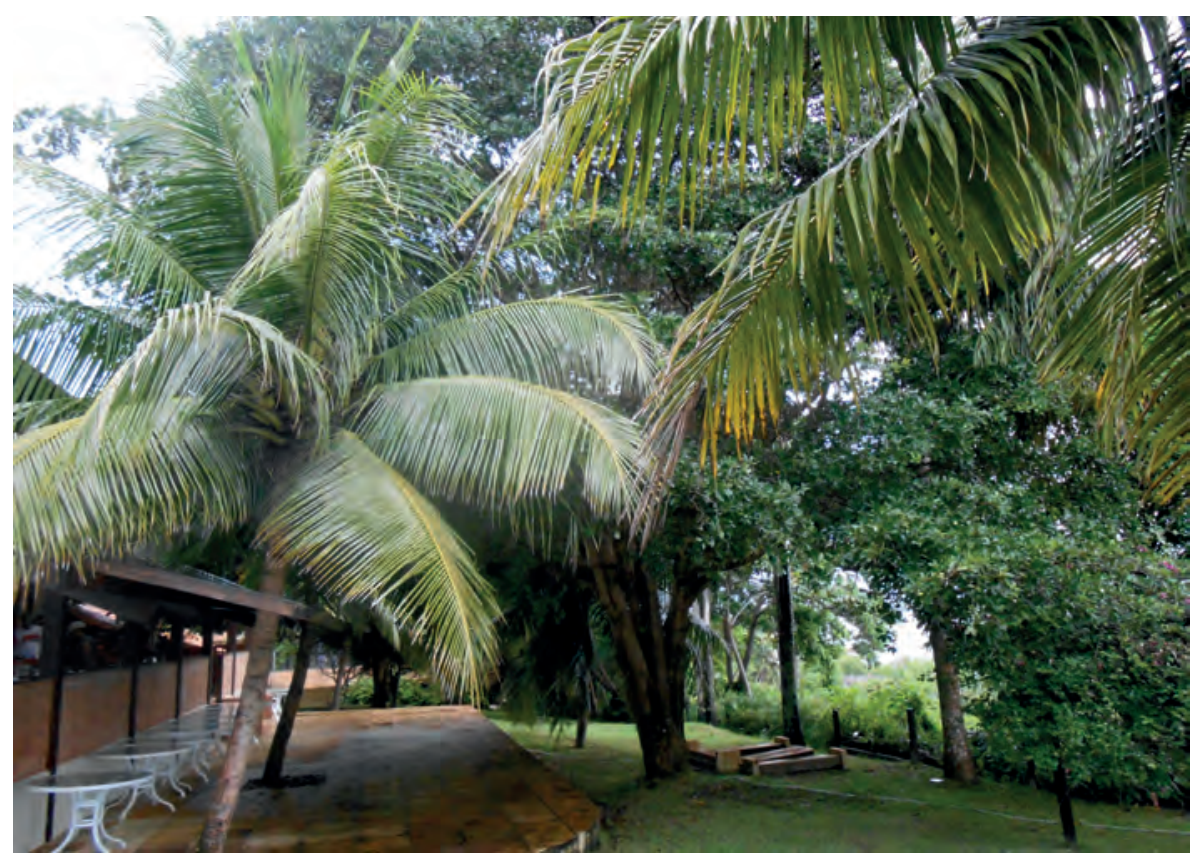

Fonte: Guerra (mar. 2014) 
IC, 30 anos, natural de Ananindeua, Pará, funcionário do resort há 6 anos, perguntado $^{7}$ sobre a idade das plantas, afirma que elas lá estão desde o início do estabelecimento, há mais de 20 anos. O estabelecimento hoteleiro era conhecido anteriormente como "Gringo Louco", de propriedade de um estrangeiro que o vendeu para a cadeia que o administrava no momento desta pesquisa.

\section{IDENTIFICAÇÃO BOTÂNICA DA PLANTA NO DISTRITO DE CUIARANA}

Depois de obter informações de moradores das localidades onde se encontraram os exemplares citados e da referência que a cuiaraneira, em Cuiarana tem, em 9 de novembro de 2013, às 6h30min, equipado com tesoura de poda, prensa, caderno de anotações e lapiseira, bateu-se à porta do restaurante e conseguiu-se acesso para coletar ramos com folhas, flores e frutos da cuiaraneira, adicionando-se informações fornecidas pelo funcionário do lugar onde ela medra, soberana. Os seus pontos de georreferência são 0³9'03.70"'S e 47 15'43,67'O.

É uma árvore de aproximadamente $12 \mathrm{~m}$ de altura, $1,35 \mathrm{~m}$ de perímetro à altura do peito, encravada na base da encosta onde se encontra a construção de edifício que tinha servido de habitação, transformado em 2013 para servir de restaurante. Possui uma trifurcação do tronco, sendo a principal delas conservada e que dá a copa da árvore. As outras duas ramificações se encontram em processo de apodrecimento. Sua preservação tem sido determinada por sua representatividade enquanto denominadora do local, o que ganha força simbólica com a adição de elementos mitológicos como a presença de animais a que se atribuem poderes mágicos, no caso uma mucura branca (Didelphis marsupialis) e um camaleão dourado. Segundo versão de um pescador habitante do local, estes animais seriam o mesmo ente, ora sob a forma de mucura, ora sob a de camaleão. Estes animais são objeto de caça e servem de alimentação em algumas comunidades amazônicas conforme se referem Azevedo e Barros (2013, p. 862879), porém em Cuiarana são referidos como personagens sagrados, aos quais se atribui a proteção do porto. Uma interpretação que poderia ser feita é que a árvore não pode ser eliminada ou maltratada por se tratar de morada daqueles encantados $^{8}$. Embora tenha sido feito referência aos animais em diversas narrativas de habitantes locais, sempre que perguntados aos narradores estes não confirmaram ter sido testemunhas oculares destas presenças, tampouco

Entrevista feita no Amazônia Atlântico Hotel Resort em 23 de março de 2014.

8 Sobre os encantados, ver Maués (1990, p. 87), que em seu trabalho identifica várias categorias fazendo link com esta análise, o encantado da mata e o encantado do fundo. Ver também Pacheco (2010), citando Prandi (2006). 
foi constatada a existência física dos mesmos. O fato é que se materializa na planta versões simbólicas em que a árvore aparece associada ao local, dando-lhe identidade e acenando com significados de proteção e conforto físicos (sombra, frescor) e espiritual complementados com as figuras do reino animal já referidas.

No momento da coleta botânica, havia flores e frutos, além de um excelente aspecto vegetativo da planta, conforme se pode verificar na Figura 5.

Figura 5 - A cuiaraneira do porto de Cuiarana

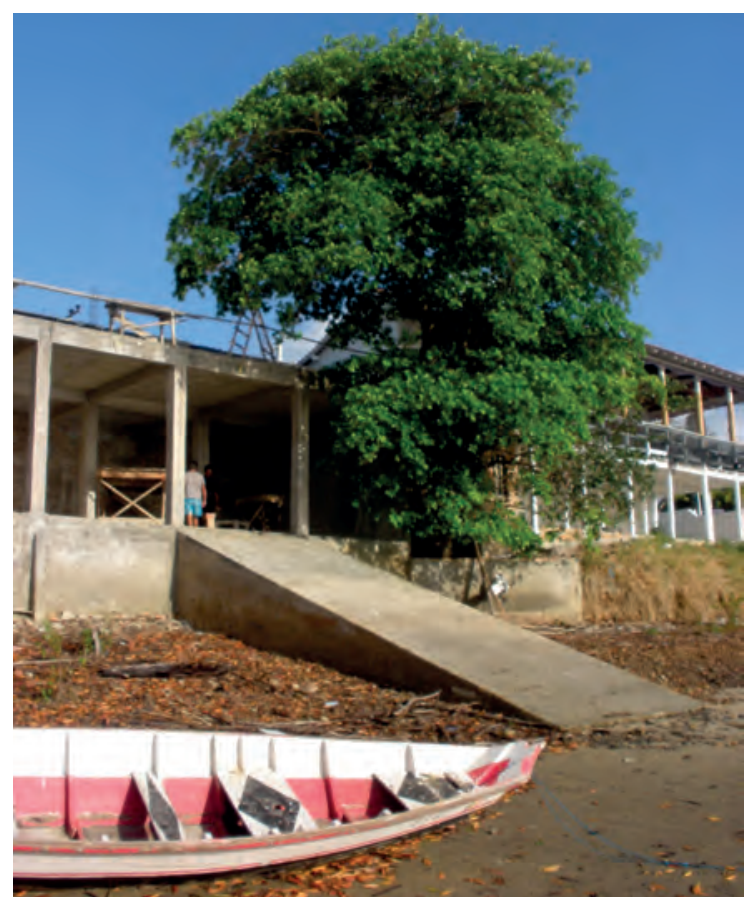

Fonte: Guerra (mar. 2014)

Coletadas partes da planta, seguindo o indicado por Fidalgo e Bononi (1989), em seguida foi encaminhado o material para o Herbário HF Profa. Normélia Vasconcelos, do Instituto de Biociências, da Universidade Federal do Pará, sendo determinados gênero e espécie pelo professor Rosildo Paiva. O material coletado permitiu a montagem de três exsicatas ficando uma no Herbário do Instituto, outro foi encaminhado para o Museu Paraense Emílio Goeldi e uma terceira ficou na coleção do Professor Gutemberg Armando Diniz Guerra. Um quarto exemplar foi coletado da mesma planta, e se encontra exposto na localidade, à sombra da cuiaraneira.

As plantas de Buchenavia grandis, Ducke são árvores de 18-50 m altura, 0,771,1 m diâmetro. Tronco cilíndrico. Folhas 4,8-8,5 cm comprimento, 3,5-4 cm 
largura, obovadas, ápice arredondado ou levemente emarginado, base cuneada, levemente decurrente, glabras, com tricomas combretáceo-compartimentados esparsos na nervura primária em ambas as faces, coriáceas, padrão de nervação do tipo camptódromo com 5-7 pares de nervuras secundárias, formando um ângulo agudo, ascendentes e levemente curvadas, reticulado conspícuo em ambas as faces, com domácias marsupiformes com tricomas na abertura, na axila das nervuras primária com as secundárias; 2 glândulas na base da folha ou ausentes; pecíolo 1-1,5 cm comprimento, pubérulo. Frutos elípticos, ápice arredondado ou diminutamente apiculado, curtamente estipitados na base, glabros, 1,6-1,8 cm comprimento, 1-1,5 cm largura. Pedúnculo frutífero pubérulo, 2,2-4,5 cm comprimento (MARQUETE; VALENTE, 2005).

Com as informações conseguidas nesta busca, pôde-se enumerar os exemplares que constam no Quadro 1.

Quadro 1 - Indivíduos de cuiaraneiras em Salinópolis, localização e georreferenciamento

\begin{tabular}{|c|c|c|}
\hline $\mathbf{N}^{o}$ & Localização & $\begin{array}{l}\text { Georreferen- } \\
\text { ciamento }\end{array}$ \\
\hline 1 & Porto de Cuiarana & $\begin{array}{l}0^{\circ} 39^{\prime} 03.70 " \mathrm{~S} \\
47^{\circ} 15^{\prime} 43,67 ” \mathrm{O}\end{array}$ \\
\hline 2 & Amazônia Atlântico Hotel Resort (próxima à piscina) & \begin{tabular}{|l|}
$0^{\circ} 39^{\prime} 12.02 ” \mathrm{~S}$ \\
$47^{\circ} 15^{\prime} 47.96 ” \mathrm{O}$ \\
\end{tabular} \\
\hline 3 & Amazônia Atlântico Hotel Resort (próxima à piscina) & $\begin{array}{l}\text { 0' 39'12.09'” } \\
47^{\circ} 15 ' 48.12 \text { 'O } \\
\end{array}$ \\
\hline 4 & Amazônia Atlântico Hotel Resort (atrás do restaurante) & \begin{tabular}{|l|}
$0^{\circ} 39^{\prime} 11.03^{\prime \prime} \mathrm{S}$ \\
$47^{\circ} 15^{\prime} 47.277^{\prime \prime} \mathrm{O}$ \\
\end{tabular} \\
\hline 5 & Rua Márcio Sousa Melo, s/n (Ronildo) & $\begin{array}{l}0^{\circ} 39^{\prime 1} 10.49 ” \mathrm{~S} \\
47^{\circ} 16^{\prime} 02.45 " \mathrm{O}\end{array}$ \\
\hline 6 & $\begin{array}{l}\text { Entrada da Praia do Farol Velho } \\
\text { Rua Verde Mar, } 448\end{array}$ & \begin{tabular}{|l|}
$0^{\circ} 35^{\prime} 33.04 " \mathrm{~S}$ \\
$47^{\circ} 19^{\prime} 08.26^{\prime \prime} \mathrm{O}$ \\
\end{tabular} \\
\hline 7 & Residência ao lado do Restaurante Marujo’s no Farol Velho & $\begin{array}{l}0^{\circ} 35^{\prime} 33.83 ” \mathrm{~S} \\
47^{\circ} 19^{\prime} 07.02^{\prime \prime} \mathrm{O}\end{array}$ \\
\hline 8 & Rua da Pousada Farol Velho & $\begin{array}{l}\text { 0'35'31.40"S } \\
47 \text { 7'19'15.74"O }\end{array}$ \\
\hline 9 & Ronco do Mar (ao lado do Hotel Atalaia Inn no Farol Velho) & $\begin{array}{l}0^{\circ} 35^{\prime} 32.48 \text { 'S } \\
47^{\circ} 19 ' 10.07 " \mathrm{O}\end{array}$ \\
\hline 10 & Ronco do Mar (ao lado do Hotel Atalaia Inn no Farol Velho) & $\begin{array}{l}0^{\circ} 35^{\prime} 32.48^{\prime \prime} \mathrm{S} \\
47^{\circ} 19 ' 10.07 " \mathrm{O}\end{array}$ \\
\hline 11 & Ronco do Mar (ao lado do Hotel Atalaia Inn no Farol Velho) & $\begin{array}{l}0^{\circ} 35^{\prime} 32.48^{\prime \prime} \mathrm{S} \\
47^{\circ} 19 ' 10.07 ” O\end{array}$ \\
\hline 12 & Ao lado da Ronco do Mar (na praia do Farol Velho) & \begin{tabular}{|l|}
$0^{\circ} 355^{\prime} 32.30^{\prime \prime} \mathrm{S}$ \\
$47^{\circ} 19^{\prime} 10.58^{\prime \prime} \mathrm{O}$ \\
\end{tabular} \\
\hline 13 & Ao lado da Ronco do Mar (na praia do Farol Velho) & $\begin{array}{l}0^{\circ} 35^{\prime} 32.30^{\prime \prime} \mathrm{S} \\
47^{\circ} 19 ' 10.58^{\prime \prime} \mathrm{O}\end{array}$ \\
\hline
\end{tabular}

Fonte: Trabalho de campo (2013; 2014) 
Com as verificações feitas, é provável que haja um número bem maior do que o repertoriado no início desta pesquisa, exigindo um trabalho de inventariamento para dar conta do número de indivíduos existentes no município.

\section{USOS DA CUIARANA}

O que se encontra na literatura sobre a planta é que ela tem madeira com densidade que lha torna importante emissora de carbono para a atmosfera no caso de sua supressão e queima (NOGUEIRA et al. 2007) e cobiçada para utilidades como esteios, mourões e estacas, principalmente na construção de currais de pesca.

Entre as pessoas entrevistadas nos locais em que havia indivíduos desta espécie, a referência é ambiental, atribuindo invariavelmente a oferta de sombra como sua maior qualidade, uma proteção emblemática do terreno e uma estética encantadora.

No caso específico da localidade denominada Cuiarana, ressalta-se a importância e proeminência de uma árvore dessa espécie, em posição estratégica, ainda que em espaço privatizado, mas com possibilidade de acesso e contemplação pela praia.

Um dos exemplares é associado a um grande guarda sol, ao mesmo tempo em que serve de teto. Outro exemplar, além da sombra, serve também de suporte para equipamentos de repouso como redes e cadeiras de balanço penduradas na árvore. A multipla utilidade que tem sido dada às árvores dessa espécie justificam uma proeminencia desta sobre outras nativas.

\section{CONSIDERAÇÕES FINAIS}

Motivado pelas falas ressaltando a existência de uma cuiaraneira no povoado que teria herdado o nome justamente de um indivíduo que permanece no local próximo ao porto do distrito de Cuiarana, foi iniciado um procedimento de perguntas sobre a ocorrência de plantas da mesma espécie na localidade e no município. As primeiras respostas foram de que há um processo sistemático de eliminação das plantas desta espécie por não se reconhecer nela virtudes que justifiquem a sua permanência nos terrenos. Ao avançar na investigação, verificou-se que há exemplares localizados em espaços de lazer, públicos e privados, tanto no povoado de Cuiarana como na praia do Farol Velho, com uma aparente valorização daqueles indivíduos ali plantados, reconhecendo-se neles não apenas o aspecto ambiental, mas também o seu valor estético. Não foram 
referidos nem identificados exemplares utilizados sistematicamente em áreas abertas, como em logradouros públicos, ficando a interrogação se o processo de preservação dos exemplares repertoriados seria intencional e uma das causas, senão a principal, desta preservação.

Os mesmos entrevistados, que em um primeiro momento ofereceram informações limitadas, nas entrevistas seguintes ampliaram as pistas, favorecendo aumentar o repertório de plantas ocorrentes neste espaço. Chegou-se a contar e repertoriar com georreferenciamento e descrever neste ensaio, treze indivíduos, todos sendo valorizados na localidade servindo como plantas ornamentais e amenizadoras do clima tropical para os banhistas e os residentes neste município.

Um investimento mais consistente sobre esta planta mostra-se necessário para que se possa esclarecer a densidade de sua inserção no litoral paraense e o seu melhor aproveitamento como planta promotora de sombra, abrigo e estética nos logradouros públicos e privados.

A representação positiva que é feita da planta indica que outros exemplares devem estar sendo utilizados e necessitaria de uma varredura para repertoriar a população existente das mesmas no município, além de se verificar outros aspectos de sua biologia.

Em que pese a dificuldade de reprodução e cultivo das cuiaraneiras, tem havido a reprodução e plantio delas, ainda que em pequenas quantidades, revelando-se um movimento de resistencia cultural que reproduz e garante a conservação dessa espécie.

\section{REFERÊNCIAS}

AZEVEDO, P.; BARROS, F. B. de. Comida, remédio, renda: conhecimentos e usos da mucura (Didelphis marsupialis) por comunidades ribeirinhas na várzea amazônica. Amazônica Revista de Antropologia, Belém, v. 5, n. 3, Especial, p. 862-878, dez. 2013.

CERVO, A. L.; BERVIAN, P. A. Metodologia científica. 4. ed. São Paulo: Makron Books, 1996.

CONSTANZA, R.; D'ARGE, R. The value of the world 's ecosystem services and natural capital. Nature, v. 387, Issue 6630, p. 253-260, 1997.

FIDALGO, O.; BONONI, V. L. R. Técnicas de coleta, preservação e herborização de material botânico. São Paulo: Instituto de Botânica de São Paulo, 1989. (Série Documentos) 
IBGE. Censo demográfico. Sinopse 2010. Disponível em: http://www. censo2010.ibge.gov.br/sinopse/index.php?uf $=15 \&$ dados $=0$. Acesso em: 12 ago. 2014.

LIVING beyond our means. Natural assets and human well being. Milleniun Ecosystem Assessment, Section 2.7., 2005. Disponível em: <http://www. millenniumassessment.org/documents/document.429.aspx.pdf $>$. Acesso em: 18 maio 2010.

MARQUETE, N. F. da S.; VALENTE, M. C. Flora da Reserva Ducke: Combretaceae. Rodriguésia, Rio de Janeiro, v. 56, n. 86, p. 131-140, 2005.

MAUÉS, R. H. A ilha encantada. Medicina e xamanismo numa comunidade de pescadores. Belém: UFPA, 1990.

NOGUEIRA, E. M.; FEARNSIDE, P. M.; NELSON, B. W.; FRANÇA, M. B. Wood density in forests of Brazil's 'arc of deforestation': Implications for biomass and flux of carbon from land-use change in Amazonia. Forest Ecology and Management, v. 248, n. 3, p. 119-135, 2007.

PACHECO, A. S. Encantarias afro-indígenas na Amazônia marajoara: narrativas, praticas de cura e (in)tolerâncias religiosas. Horizonte, Belo Horizonte, v. 8, n. 17, p. 88-108, abr./jun. 2010. 